\title{
Modulatory efficacy of Punica granatum L. powder ethanol extract (PLEE) on lead acetate-induced hepatic and renal toxicity
}

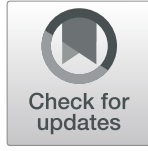

\author{
Oluwaseun Abraham Adebisi ${ }^{1}$, Wasiu Bolade Agbaje ${ }^{2}$ and Omowumi Oyeronke Adewale ${ }^{\text {* }^{*}}$
}

\begin{abstract}
Background: Pomegranate powder derived from pomegranate fruit contains phytochemicals chief of which is ellagitannins. Owing to their high antioxidative capabilities we investigated its efficacy against lead acetate induced hepatic and renal toxicity.

Methods: Pomegranate powder $(500 \mathrm{~g})$ was procured and soaked in 1 Litre of ethanol for three days, its filtrate was concentrated and freeze dried to form Punica granatum L. ethanol extract (PLEE). Thirty (30) male albino Wistar rats with average weight between $140 \pm 20 \mathrm{~g}$ were used for this study. They were equally shared into 6 groups with 5 animals each; A: Control; B: Lead acetate only C: Lead acetate + PLEE (1); D: Lead acetate + PLEE (2); E: PLEE (1) and F: PLEE (2). Serum, liver and kidney samples were obtained for biochemical assays. The integrity of liver and kidney tissues were also accessed.
\end{abstract}

Results: Lead administration resulted in marked elevations in liver transaminases in serum and liver as well as a significant increase in kidney function markers in the serum and kidney $(p<0.05)$. There was also a significant decline in average body weight, antioxidant markers in the liver and kidney of Wistar rats while there was a significant increase in lipid peroxidation levels in both liver and kidney. However, administration of PLEE at different doses significantly modulated these changes.

Conclusion: Lead acetate administration led to hepatic and renal toxicity as evident by alterations in liver and kidney function markers, antioxidant status and tissue integrity. However, PLEE can combat these toxicities.

Keywords: Lead acetate, Punica granatum L., Pomegranate powder, Hepatotoxicity, Renal toxicity, Oxidative stress

\section{Introduction}

Lead toxicity is a significant health challenge because of its appropriation in nature and living things [1]. Humans can be exposed to lead via sources that include edible items, drinking water, dust, petroleum products amongst others [2]. Majorly, organs like the liver, kidney, brain, blood and the immune system are adversely affected by lead poisoning or plumbism. People who are greatly at risk of health challenges due to lead toxicity including pregnant women, children and city occupants. Lead

\footnotetext{
* Correspondence: adewaleomowumi13@gmail.com

${ }^{1}$ Department of Biochemistry, Faculty of Basic and Applied Sciences, Osun

State University, Osogbo, Nigeria

Full list of author information is available at the end of the article
}

induces an array of physiological and biochemical dysfunctions [3]. A few attempts have been made by scientists to elucidate lead-instigated toxicity although the precise route by which lead induces its toxicity has not been fully elucidated. However, several of the proposed mechanisms revolves around the generation of reactive oxygen species (ROS) that ultimately results in oxidative stress with ensuing lipid peroxidation.

Oxidative stress reflects a lopsidedness in the concentration of certain reactive species as compared to the system's ability to repair the resulting damage or promptly detoxify the reactive intermediates [4]. Several disorders including cancer have been linked to oxidative stress while free radicals such as reactive oxygen species

\section{Springer Open}

(ㅇ The Author(s). 2022 Open Access This article is licensed under a Creative Commons Attribution 4.0 International License, which permits use, sharing, adaptation, distribution and reproduction in any medium or format, as long as you give appropriate credit to the original author(s) and the source, provide a link to the Creative Commons licence, and indicate if changes were made. The images or other third party material in this article are included in the article's Creative Commons licence, unless indicated otherwise in a credit line to the material. If material is not included in the article's Creative Commons licence and your intended use is not permitted by statutory regulation or exceeds the permitted use, you will need to obtain permission directly from the copyright holder. To view a copy of this licence, visit http://creativecommons.org/licenses/by/4.0/. 
(ROS) and reactive nitrogen species (RNS) have been implicated in their aetiology. However, the defence mechanism of the body which include antioxidants against ROS could be overwhelmed in many circumstances by an over-production of these species [5].

Naturally, antioxidants can be classified as enzymatic and non-enzymatic. Catalase, glutathione peroxidase, and superoxide dismutase are produced within the cells and are referred to as enzymatic antioxidants however carotenoids, flavonoids, vitamins, minerals, etc. are majorly found in vegetables, fruits, nuts, some grains etc. and are referred to as non-enzymatic [6]. Enzymatic antioxidants scavenge free radicals and lipid peroxides, thereby detoxifying them [3]. Natural compounds that possess antioxidative capacities contribute to the protection of the system against free radicals' deleterious effects these compounds include flavonoids which are present in medicinal plants and human diet in great proportions. Consequently flavonoids are of great value in research for their hepato-protective, antibacterial and antioxidative activities [7].

The term medicinal plants include different kinds of plants utilized for herbalism and a portion of these plants have restorative and therapeutic activities. These plants are the "mainstay" of customary medicines, more than 3.3 billion individuals in the less evolved nations use them consistently. One of these therapeutic plants includes the pomegranate plant (Punica granatum L.) which is sometimes known as Ruman plant [8]. Punica granatum L. develops for the most part in Mediterranean borders, Asia, and American. It is viewed as perhaps the most seasoned products of the soil and one of the first to be incorporated in the human diet. The pericarp, the inward lamella, and the part devoured comprise 38, 10 and $52 \%$ respectively of the absolute weight. The juice is $78 \%$ of the segment utilized (45-61\% of all-out weight) and the seeds are $22 \%[9,10]$. Pomegranates are normally eaten fresh; nonetheless, they are likewise a wellspring of juice and molasses. The juice contains a lot of sugars, ascorbic acids, vitamin B, gelatin, cellulose, tannins, and ash. Additionally, the pericarp is a good wellspring of polyphenols, for example, anthocyanin, leucoanthocyanins, catechins, and flavonoids and contains around $30 \%$ of tannins. Punica granatum L. is rich in polyphenols, in particular ellagitannins, which are natural antioxidants. Ellagitannins in Punica granatum L. are effective in powder form as in juice form [10]. A 2010 issue of "Disease Prevention Research" expressed that ellagitannins from Punica granatum L. showed anticancer capacities by halting the development and expansion of breast cancer tumours in an in vitro investigation [11]. Punica granatum L. beneficial effects has been studied in the context of xenobiotics induced toxicity pertaining to the hepatic and renal tissues [12-15]. Lavoro et al. [14] in a recent review highlighted the potential benefits of pomegranate against common chronic diseases and their risk factors. Presently, there has been no reports available on the modulatory efficacy of PLEE on lead-induced hepatorenal toxicity despite the fairly numerous research on its medicinal properties. In view of this, the present study was designed to elucidate the modulatory efficacy of on lead-induced hepatorenal toxicity in Wistar rats.

\section{Materials and methods}

\section{Chemicals and reagents}

Punica granatum L. powder (500 g) was procured from the Islhahudeen central mosque, Alekuwodo area, Osogbo, Osun State. Reagents for analysis such as Alanine aminotransferase (ALT), Aspartate Aminotransferase (AST), Urea and creatinine were gotten from Randox Laboratories Ltd Crumlin, United Kingdom. Other reagents including dipotassium hydrogen phosphate trihydrate, thiobarbituric acid (TBA), trichloroacetic acid (TCA), 5', 5'-dithiobis-2-nitrobenzoic acid (DTNB), 1-choro-2.4 dinitrobenzene (CDNB), glutathione (GSH) and lead ;were procured from Sigma Aldrich. All reagents were of analytical grade.

Preparation of Punica granatum L. ethanol extract (PLEE) Punica granatum L. powder (500 g) was soaked in 1 Liter of ethanol $(50 \%)$ at $25{ }^{\circ} \mathrm{C}$ for three days with

Table 1 Changes in the body weights of experimental animals exposed to Lead acetate and treated with PLEE. N = 5

\begin{tabular}{lllll}
\hline Treatment & Body weights & & Weight Gained (\%) & $\begin{array}{l}\text { Liver } \\
\text { weights } \\
\text { (g) }\end{array}$ \\
\cline { 2 - 5 } & Initial Body Weight (g) & Final Body Weight (g) & $\begin{array}{l}\text { Relative } \\
\text { liver } \\
\text { weights }\end{array}$ \\
\hline CONTROL & $125.4 \pm 1.8$ & $146 \pm 2.5$ & 14.11 & $3.38 \pm 0.05$ \\
LEAD ONLY & $159.6 \pm 5.0^{*}$ & $142 \pm 8.8^{*}$ & -12.39 & $5.22 \pm 0.05^{*}$ \\
LEAD + PLEE (DOSE 1) & $147.4 \pm 4.0^{*}$ & $166 \pm 9.8^{*}$ & 11.20 & $3.68 \pm 0.2^{*}$ \\
LEAD + PLEE (DOSE 2) & $128.4 \pm 3.8$ & $148 \pm 6.9$ & 13.24 & $3.44 \pm 0.04$ \\
PLEE (DOSE 1) & $135.2 \pm 3.5^{*}$ & $168 \pm 4.9^{*}$ & 19.52 & $3.07 \pm 0.3$ \\
PLEE (DOSE 2) & $137.6 \pm 2.0^{*}$ & $163 \pm 3.3^{*}$ & 15.58 & $3.38 \pm 0.04$ \\
\hline
\end{tabular}


agitations at intervals to facilitate proper extraction. The mixture was then filtered using a muslin cloth and the filtrate was collected in bottles and tightly sealed. The filtrate was concentrated using a rotary evaporator and lyophilized using a freeze dryer to concentrate adequately at central science laboratory, Obafemi Awolowo University, Ile-ife Osun state. The concentrated extract was collected and used for this study. A percent yield of $82.13 \%$ for the PLEE extract was obtained upon lyophilisation.

\section{Experimental animals \\ Experimental design}

Thirty (30) Wistar strain albino rats with average age of $10-12$ weeks and weights of $140 \pm 20 \mathrm{~g}$ were randomly distributed into six groups of five animals per group and acclimatized. Group 1 was the control group which received feed and water ad-libitum, group 2 received lead acetate $(30 \mathrm{mg} / \mathrm{kg})$ during the research. Group 3 received lead acetate $(30 \mathrm{mg} / \mathrm{kg})$ and was treated with 100 $\mathrm{mg} / \mathrm{kg}$ of Punica granatum L. ethanol extract (PLEE) group 4 received $30 \mathrm{mg} / \mathrm{kg}$ of lead acetate $(30 \mathrm{mg} / \mathrm{kg})$ and PLEE $(200 \mathrm{mg} / \mathrm{kg})$ for a period of 2 weeks. Group 5 and Group 6 received PLEE $100 \mathrm{mg} / \mathrm{kg}$ and $200 \mathrm{mg} / \mathrm{kg}$ of PLEE respectively for a period of 2 weeks. Administration was done orally for total period of 3 weeks.

\section{Determination of body and relative liver weight}

Digital chemical weighing balance was used to record the body weight of experimental animals before the commencement of the study and after the end of the last administration, and the mean body weight correspondingly computed. Weight changes were expressed as percentage weight increase. Percentage weight increase was extrapolated from the mathematical expression;

$$
\frac{W y-W x}{W y} \times 100
$$

Where Wy $=$ Final weight and $\mathrm{Wx}=$ initial weight

\section{Serum preparation}

Following the termination of the experiment, each rat's blood was collected into samples bottles without anticoagulants through cardiac puncture and thereafter centrifuged at $3000 \mathrm{~g}$ for 15 mins. The resulting serum was used for biochemical assays.

\section{Collection of tissue samples and preparation of sub-cellular fractions}

Following the termination of the experiment, the liver and kidney tissues were excised and rinsed in ice-cold $1.15 \% \mathrm{KCl}$, blotted dry and weighed. The tissues were

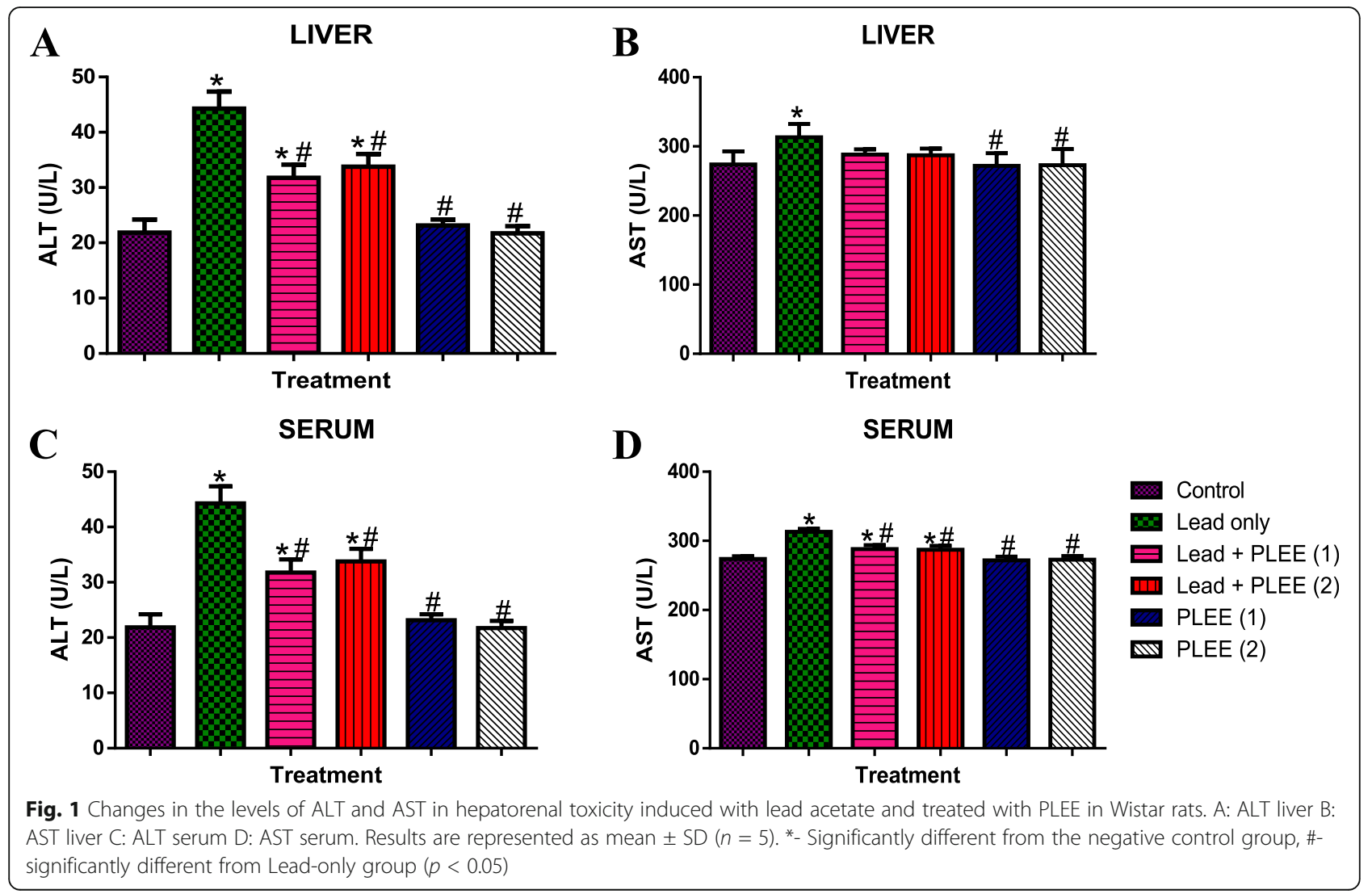


kept in properly labelled bottles for biochemical assays. The liver tissues were weighed, macerated and homogenized in 4 volumes of ice-cold $0.25 \mathrm{M}$ sucrose. The homogenates were centrifuged at $10000 \mathrm{~g}$ at $-4{ }^{0} \mathrm{C}$ for 15 mins using high-speed refrigerated centrifuge (TGL16G). The supernatant termed the "post-mitochondria fractions" (PMF) was obtained and stored for subsequent analysis.

\section{Biochemical analyses}

\section{Protein determination}

Plasma and tissue homogenate protein concentration was determined by the Biuret method as described by Gornall et al., [15].

\section{Determination of Alanine Aminotransferase (ALT) activity}

Following the principle described by Reitman \& Frankel, [16] the levels of ALT was determined using Randox kits.

\section{Determination of Aspartate Aminotransferase (AST) activity} In tandem with the principle described by Reitman \& Frankel, [16] AST levels were determined using Randox kits.

\section{Estimation of Urea}

Urea level was determined as described by UreaseBertherlot method as described by Richterich \& Kuffer, (1973) with Randox kits.

\section{Estimation of Creatinine}

Creatinine level was determined as described by Jaffe's method as described by Delanghe \& Speeckaert, [17] using Randox kit

\section{Estimation of Catalase activity}

Following the method as described by Sinha, [18] the activities of catalase was assessed.

\section{Evaluation of reduced Glutathione (GSH) level}

The procedure as described by Jollow et al. [19] was adopted in estimating the level of reduced glutathione in the samples

\section{Determination of Glutathione-S-Transferase (GST) activity}

Glutathione-S-transferase activity was determined using the method of Habig et al. [20]

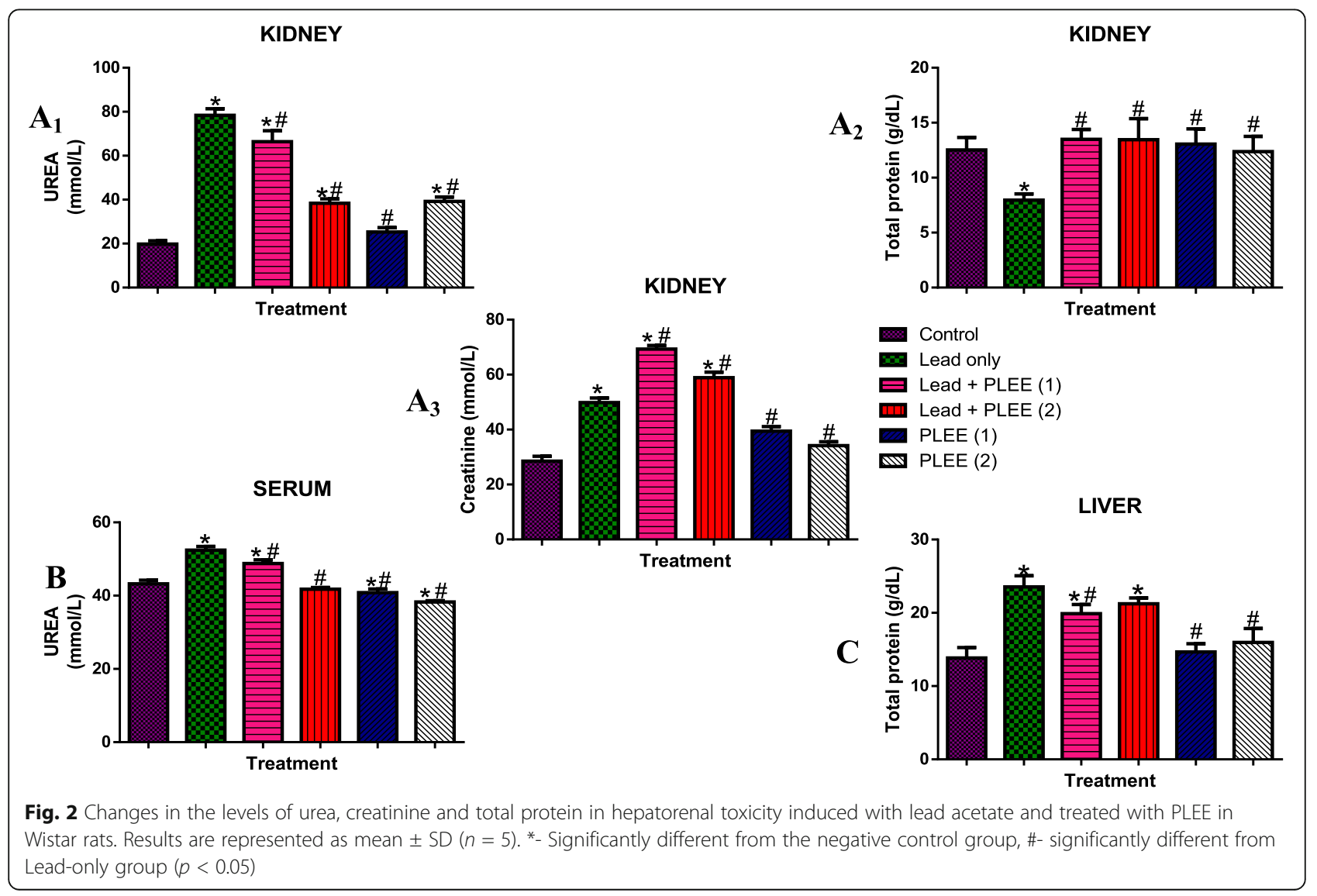




\section{Assessment of Lipid Peroxidation (LPO)}

The procedure as described by Ádám-Vizi and Seregi, [21] was used to access Lipid peroxidation by measuring the thiobarbituric acid reactive (TBAR) products present in the test sample and expressed as micromolar of malondialdehyde (MDA) /g tissue.

\section{Statistical analysis}

Data obtained from this study are expressed as mean \pm standard deviation (SD). One-way analysis of variance (ANOVA) was used to access difference between means followed by Tukey's multiple comparison test. GraphPad Prism 6.0 was the statistical package used for the analysis $p$-values $<0.05$ were considered statistically significant for differences in means.

\section{Results}

Exposure to lead acetate leads to significant weight loss in experimental animals

Administration of lead for one week led to significant weight loss as shown in Table 1 However, coadministration of lead and PLEE led to weight gain. However, administration of PLEE at both doses also led to significant weight gain. Also, there was a significant increase in Liver weight of lead-exposed animals when compared to control $(p<0.05)$.
PLEE beneficially modulates transaminases in lead acetate-induced toxicity in liver and serum of Wistar rats We observed that lead administration led to an increase in the level of transaminases (ALT and AST) in the liver (Fig. 1A and B) and serum (Fig. 1C and D) of exposed Wistar rats when compared with control $(p<0.05)$. However, co-administration of PLEE at two different doses modulated the levels when compared to both positive and negative controls. Also, only PLEE administration at both doses was not significantly different from negative control $(p<0.05)$ but led to a significant difference when compared to the positive control group $(p<0.05)$.

\section{PLEE modulates renal markers and total protein in lead-} induced hepatorenal damage

We also observed that lead administration led to the significant changes in renal markers as there was a significant increase in urea (Fig. $2 \mathrm{~A}_{1}$ and $\mathrm{B}$ ) and creatinine (Fig. $2 \mathrm{~A}_{3}$ ) levels in both serum and kidney homogenate $(p<0.05)$. However co-administration of PLEE and lead significantly modulates the increased levels of urea and creatinine. Similarly, administration of PLEE only led to a significant decrease in the renal markers when compared to the positive control $(p<0.05)$. Also, we recorded significant changes in the total protein in both kidney (Fig. 2A $\mathrm{A}_{3}$ ) and liver (Fig. 2C) homogenates. Co-

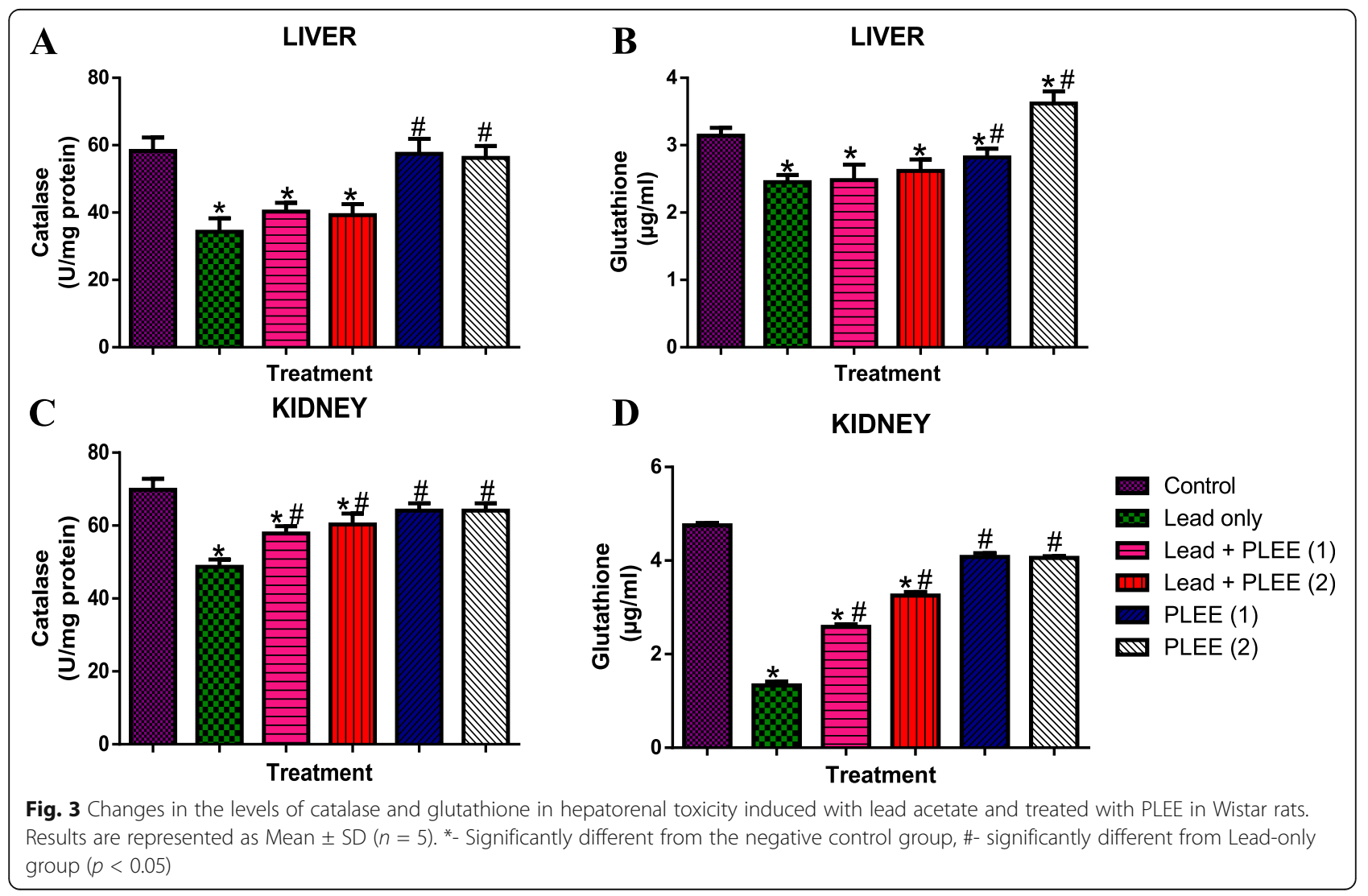


administration of lead and PLEE modulates the level of total protein in the liver and kidney. However, administration of PLEE only significantly increases the level of total protein when compared to the positive control.

\section{PLEE modulates antioxidant levels in lead-induced hepatorenal toxicity.}

Figure 3 showed that there was a significant decrease in the levels of antioxidants (Catalase and glutathione) in the positive control group when compared to the negative control $(p<0.05)$ in both liver and kidney homogenates. We also recorded significant modulation of these antioxidant levels in co-administration of lead and PLEE, especially in kidney homogenates. Similarly, PLEE administration alone at both doses led to a significant increase when compared with the positive control group only $(p<0.05)$.

PLEE modulates lipid peroxidation and GST levels in leadinduced hepatorenal toxicity.

We also recorded significant elevation in lipid peroxidation levels in both liver (Fig. 4B) and kidney (Fig. 4D) in the positive control group when compared with the negative control group $(p<0.05)$. Also, coadministration of lead and PLEE led to significant modulation of lipid peroxidation at both doses of PLEE administered. Similarly, PLEE administration alone at both doses led to a significant increase when compared with the positive control group only $(p<0.05)$. There was a significant elevation in GST levels in the negative control group compared to the positive control group $(p<$ 0.05 ) in the liver of Wistar rats (Fig. 4A) while there was a decline in the kidney of Wistar rats (Fig. 4C). Coadministration of lead and PLEE significantly modulated GST levels when compared to the positive control group. PLEE administration alone at both doses led to a significant increase when compared with the positive control group only $(p<0.05)$.

\section{Discussion}

Heavy metals such as lead are known to adversely affect body systems through a marked and sustained production of reactive nitrogen species (RNS) and reactive oxygen species (ROS). These species are able to precipitate

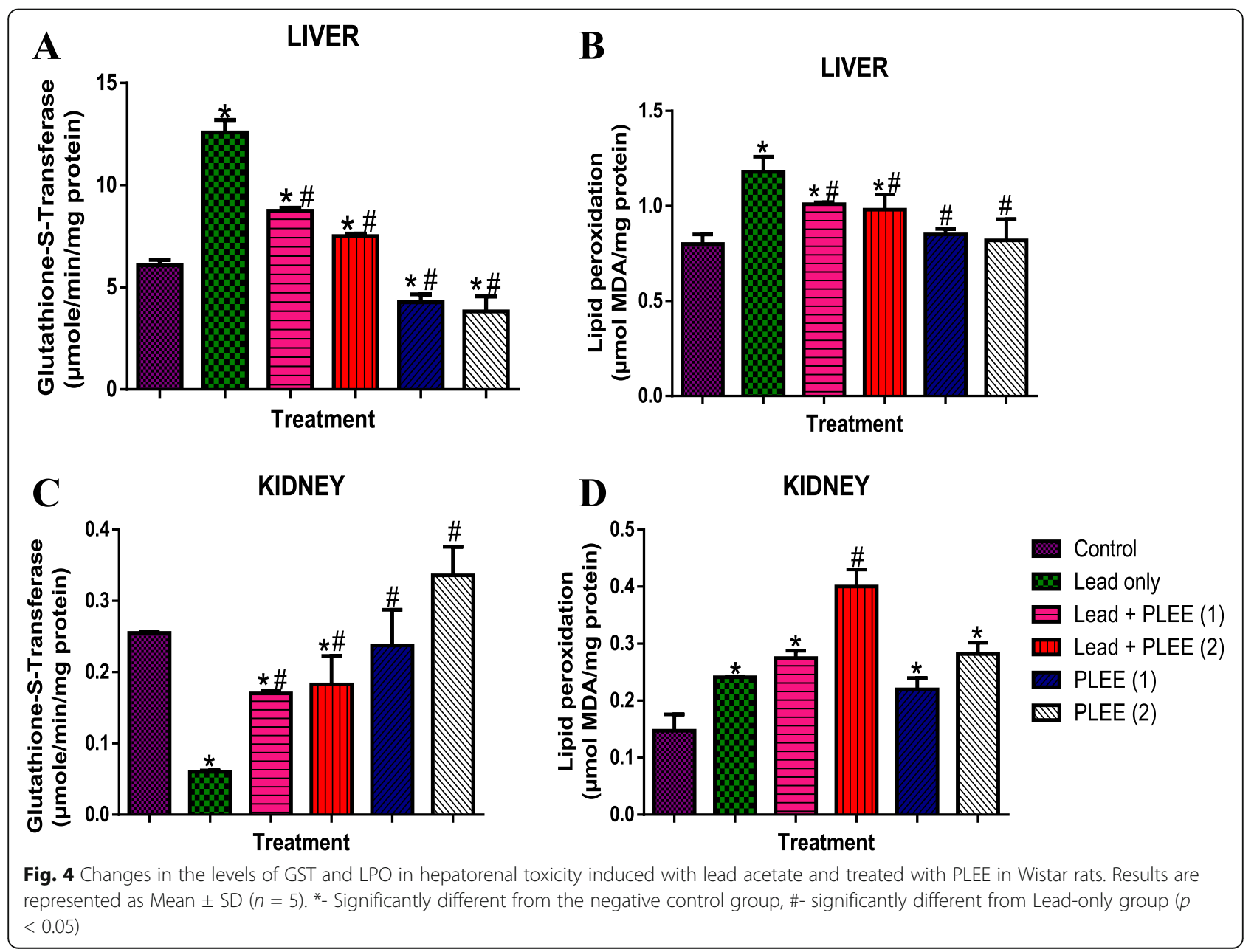



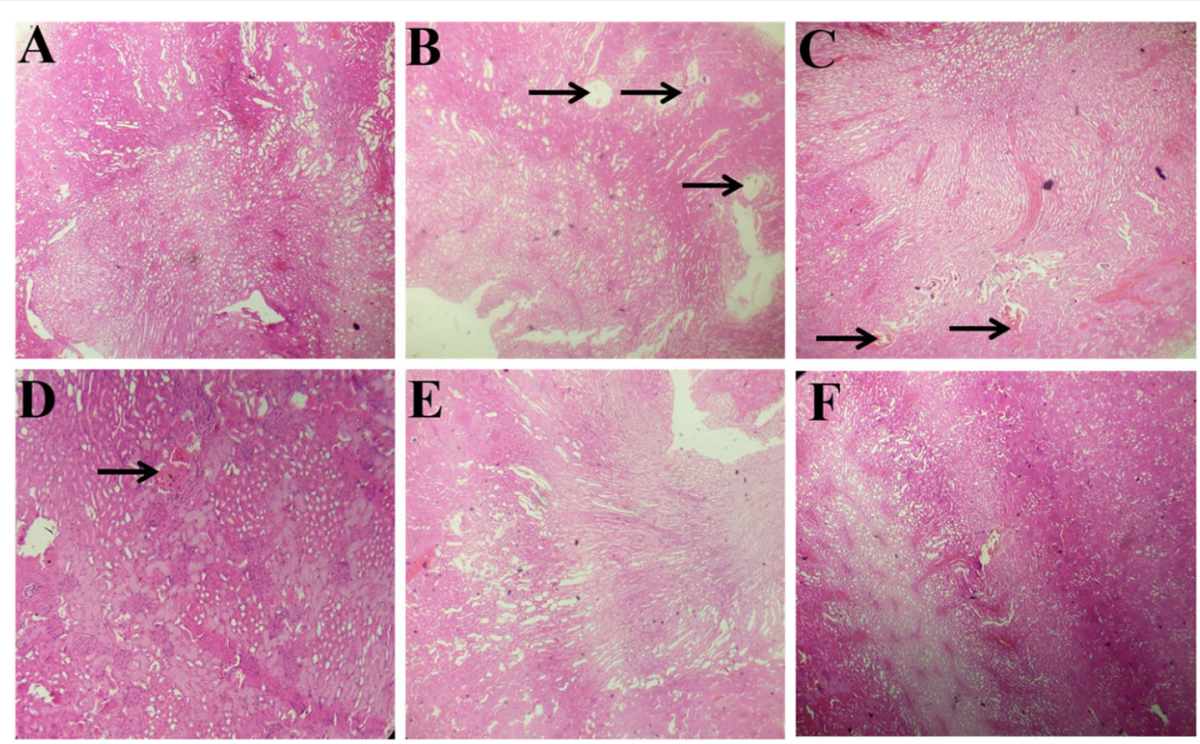

Fig. 5 Histological photomicrographs of kidney samples from Wistar rats with Lead acetate-induced toxicity and treated with PLEE (Mag., X100). A (Control group): No visible lesions seen; B (Lead only): Tubular sections appear greatly enlarged; C (Lead + PLEE (1): Moderate congestion of the renal cortex; D (Lead + PLEE (2): Mild to moderate congestion at the renal cortex; E (PLEE (1) No visible lesions are seen; F (PLEE (2): No visible lesions are seen

alterations in the structure and function of proteins, lipids, and nucleic acids. Although, during basal metabolism free radicals are generated especially in the electron transport chain during respiration, they are not produced at harmful or deleterious rates [22]. The hepatic tissue is one of the main objects of lead accumulation within living systems due to the presence of xenobiotic transforming enzymes chief of which is the cytochrome P450 superfamily and this system attempts to restore homeostasis by increasing the activities of liver function enzymes especially the transaminases [2]. Also a great deal metabolism occurs in the liver, alterations in transaminase activities are indicative of hepatic toxicity.

Significant elevation in the activities of alanine aminotransferase and aspartate aminotransferase upon exposure to lead has been documented by several researchers [23]. Administration of PLEE (100 mg/ $\mathrm{kg}$ and $200 \mathrm{mg} /$ $\mathrm{kg}$ ) was efficient to combat lead acetate toxicity as evident by a significant decline in the levels of ALT and AST, thus counteracting the potential deleterious effect of lead toxicity in Wistar rats. This is likely due to the presence of antioxidants especially ellagitannins that are able to combat hepatic toxicity.

Urea and creatinine are major excretory products of the kidney. Significant elevation of serum urea and creatinine is indicative of chronic renal damage or disease [24]. Lead acetate administration leads to a significant increase in urea and serum in the kidney and serum of Wistar rats. However, PLEE administration was efficient in combating the observed increase thereby ameliorating the damage. PLEE administration alone slightly modulated urea and creatinine levels in the kidney and serum of Wistar rats.

Treatments of Wistar rats with Lead acetate at resulted in significant weight loss which is improved significantly when treated with PLEE. Lead containing compounds and their derivatives are known to promote the induction oxidative damage in hepatocytes and kidney cells by enhancing lipid peroxidation [25]. Malondialdehyde (MDA) is a marker of lipid peroxidation and therefore of oxidative stress. Reduced glutathione is a tripeptide consisting of cysteine, glycine and glutamic acid. It can either act enzymatically as a cofactor or coenzyme by detoxifying reactive oxygen species via the enzyme glutathione peroxidase or it can acts nonenzymatically through the interactions of reactive oxygen species with sulfhydryl (SH) groups [3]. The results of this study documents a marked elevation in lipid peroxidation and a concurrent decline in glutathione level of lead acetate-treated rat liver and kidney. These observations could be as a result of the high affinity of lead to bind tightly with the sulfhydryl groups of glutathione therefore resulting in oxidative stress. Interestingly, PLEE significantly increased glutathione level and ameliorated malondialdehyde levels in Wistar rat liver and kidney treated with lead acetate. This results suggests the capacity of PLEE to attenuate oxidative stress by increasing glutathione levels and decreasing concentration of MDA in lead-treated rat liver and kidney.

Glutathione-s-transferase (GST) is a small enzyme that tightly and specifically binds to glutathione [26]. GST activity is greatly increased in Lead exposed groups due to 

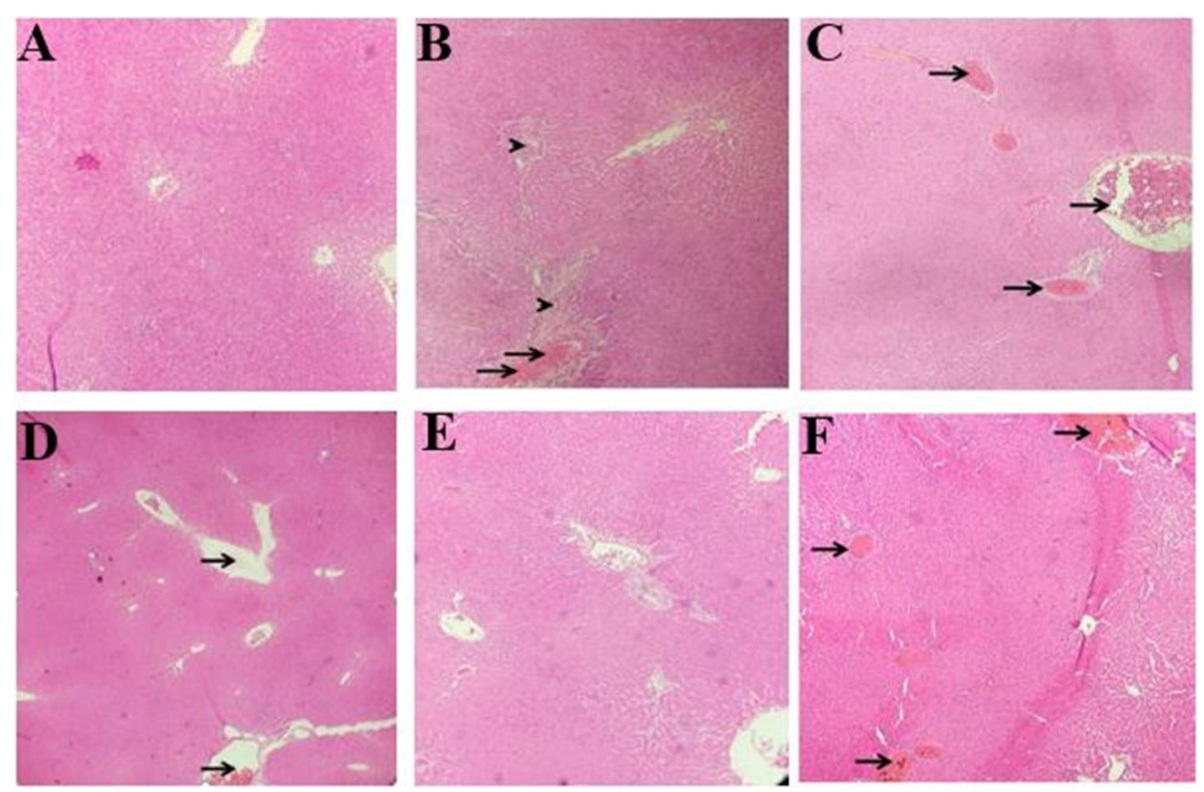

Fig. 6 Histological photomicrographs of liver samples from Wistar rats with Lead acetate-induced toxicity and treated with PLEE (Mag., X100). A (Control group): No visible lesions seen; B (Lead only): There is a mild to moderate congestion of the portal vessels (arrows). There appears to be a mild periportal fibroplasia (arrowheads); C (Lead + PLEE (1): There is a moderate to severe portal and central venous congestion; D (Lead + PLEE (2): There is mild congestion of the portal vessels; E (PLEE (1) No visible lesions are seen; F (PLEE (2): There are mild portal and central venous congestions

its affinity for GSH. The co-treated groups show a subsequent significant decrease in GST activity while exposed groups show a further decrease in GST activity when compared to the control group. The activities of many antioxidant enzymes requires the presence of cofactors that may be metals or other compounds. Interestingly, Lead compounds and their derivative have a high affinity for $\mathrm{SH}$ groups or metal cofactors in antioxidant enzymes and molecules, that precipitates a decline in the activities of antioxidant enzymes, such as catalase. Superoxide dismutase, catalase and glutathione peroxidase are pivotal in mitigating against ROS induced toxicity and a marked decline in their activities is indicative of a distortion in redox balance thereby precipitating oxidative stress [27]. Catalase is of the major enzymatic antioxidants that has heme as its prosthetic group. The systems absorption of iron in the gastrointestinal tract and heme biosynthesis is greatly reduced by Lead [28]. Catalase activity is significantly reduced in Lead exposed animals indicating that lead is contributing to oxidative stress, however, this effect is attenuated significantly by Punica granatum L. ethanol extract (PLEE) which increases catalase activity in co-treated animals when compared to Lead exposed animals. This is in line with observations in Wang et al. [29] who also reported a significant decrease in catalase activity in animals exposed to lead.

Lead administration leads to significant histopathological changes as evident by enlargement of tubular sections in hepatic tissues of Wistar rats (Fig. 5). In the kidney, there was also moderate congestion of the portal vessels as well as mild periportal fibroplasia as a result of lead administration (Fig. 6). This result is in tandem with that of Nisar et al. [30]. However, upon co-administration of PLEE with lead, there were significant changes as compared to the control suggesting that PLEE administration conferred protection on the integrity of hepatic and renal tissues. PLEE administration alone didn't result in any changes in the liver and kidney of Wistar rats.

\section{Conclusion}

This study established that, lead acetate administration led to hepatic and renal toxicities as evident by hepatorenal function markers, antioxidant status and tissue integrity. However, PLEE was found to be efficient in combating the toxicity.

\section{Recommendation}

Lead compounds are deleterious to the liver and kidney when they bio accumulate and as such their concentrations should be kept at minimal levels in the environment. PLEE from pomegranate fruit is an important source of phytochemicals that is capable to quell these toxicities hence should be encouraged in such cases.

\section{Authors' contributions}

OAA and OOA conceived and designed the study, conducted experiments, provided research materials, and collected and organized the data WJB

contributed in writing the initial draft of the manuscript and the final review 
of the manuscript. All authors have critically reviewed and approved the final draft and are responsible for the content and similarity index of the manuscript.

\section{Funding}

This research did not receive any specific grant from funding agencies in the public, commercial, or not for- profit sectors.

\section{Declarations}

\section{Ethics approva}

All procedures performed in studies involving animals were in accordance with the declaration of Helsinki as described by the College of Health Sciences ethical approval committee Osun State University, Osogbo. The handling and use of all laboratory animals were in accordance with $\mathrm{NIH}$ Guide for the care and use of laboratory animals. The authors also received external ethical approval with identification number EBS/LSR/A/11/2019/002 for the research.

\section{Competing interests}

Authors have no conflict of interest to declare.

\section{Author details}

${ }^{1}$ Department of Biochemistry, Faculty of Basic and Applied Sciences, Osun State University, Osogbo, Nigeria. ${ }^{2}$ Department of Chemistry, Faculty of Basic and Applied Sciences, Osun State University, Osogbo, Nigeria.

Received: 8 July 2021 Accepted: 30 December 2021

Published online: 28 January 2022

\section{References}

1. Xia D, Yu X, Liao S, Shao Q, Mou H, Ma W. Protective effect of Smilax glabra extract against lead-induced oxidative stress in rats. J Ethnopharmacol. 2010;130:414-20

2. El-Nekeety AA, El-Kady AA, Soliman MS, Hassan NS, Abdel-Wahhab MA. Protective effect of Aquilegia vulgaris (L.) against lead acetate-induced oxidative stress in rats. Food Chem Toxicol. 2009;47:2209-15.

3. Sivaprasad R, Nagaraj M, Varalakshmi P. Combined efficacies of lipoic acid and 2,3-dimercaptosuccinic acid against lead-induced lipid peroxidation in rat liver. J Nutr Biochem. 2004;15:18-23.

4. Al-Dalaen SM. Review Article: Oxidative Stress Versus Antioxidants. Am J Biosci Bioeng. 2014;2:60.

5. Brambilla D, Mancuso C, Scuderi MR, Bosco P, Cantarella G, Lempereur L, et al. The role of antioxidant supplement in immune system, neoplastic, and neurodegenerative disorders: A point of view for an assessment of the risk/ benefit profile. Nutr J. 2008;7.

6. Flora SJS. Nutritional components modify metal absorption, toxic response and chelation therapy. J Nutr Environ Med. 2002;12:53-67.

7. Zheleva-Dimitrova D, Nedialkov P, Girreser U, Kitanov G. Benzophenones and flavonoids from Hypericum maculatum and their antioxidant activities. Nat Prod Res. 2012;26:1576-83.

8. $\quad$ Singh A. Medicinal Plants: A Review. J Plant Sci. 2015;3:50

9. El-Nemr SE, Ismail IA, Ragab M. Chemical composition of juice and seeds of pomegranate fruit. Food Nahrung. 1990;34:601-6.

10. Derakhshan Z, Ferrante M, Tadi M, Ansari F, Heydari A, Hosseini MS, et al Antioxidant activity and total phenolic content of ethanolic extract of pomegranate peels, juice and seeds. Food Chem Toxicol. 2018;114:108-11.

11. Chalfoun-Mounayar A, Nemr R, Yared P, Khairallah S, Chahine R. Antioxidant and weight loss effects of pomegranate molasses. J Appl Pharm Sci. 2012;2: 45-50.

12. Husain $H$, Latief $U$, Ahmad R. Pomegranate action in curbing the incidence of liver injury triggered by diethylnitrosamine by declining oxidative stress via Nrf2 and NFkB regulation. Sci Rep. 2018;8.

13. Rahmani AH, Alsahli MA, Almatroodi SA. Potential antitumor effects of pomegranates and its ingredients. Pharmacogn Rev. 2017;11:136-40.

14. Lavoro A, Falzone L, Gattuso G, Salemi R, Cultrera G, Leone G, et al. Pomegranate: A promising avenue against the most common chronic diseases and their associated risk factors (Review). Int J Funct Nutr. 2021;2.

15. Gornall AG, Bardawill CJ, David MM. Determination of serum proteins by means of the biuret reaction. J Biol Chem. 1949;177:751-66.
16. Reitman S, Frankel S. A colorimetric method for the determination of serum glutamic oxalacetic and glutamic pyruvic transaminases. Am J Clin Pathol. 1957;28:56-63.

17. Delanghe JR, Speeckaert MM. Creatinine determination according to Jaffe What does it stand for? NDT Plus. 2011;4:83-6.

18. Sinha AK. Colorimetric assay of catalase. Anal Biochem [Internet]. Anal Biochem. 1972;47:389-94 Available from: https://pubmed.ncbi.nlm.nih.gov/4 556490/. Accessed Dec 2020.

19. Jollow D, Mitchell JR, Zampaglione N, Gillette JR. Bromobenzene-induced liver necrosis. Protective role of glutathione and evidence for 3,4bromobenzene oxide as the hepatotoxic metabolite. Pharmacology. 1974; 11:151-69.

20. Habig WH, Pabst MJ, Jakoby WB. Glutathione $S$ transferases. The first enzymatic step in mercapturic acid formation. J Biol Chem 1974;249:71307139

21. Ádám-Vizi V, Seregi A. Receptor independent stimulatory effect of noradrenaline on Na,K-ATPase in rat brain homogenate. Role Lipid Peroxidation Biochem Pharmacol. 1982;31:2231-6.

22. Adewale OO, Samuel ES, Manubolu M, Pathakoti K. Curcumin protects sodium nitrite-induced hepatotoxicity in Wistar rats. Toxicol Rep Elsevier 2019;6:1006-11.

23. Mehana EE, Meki ARMA, Fazili KM. Ameliorated effects of green tea extract on lead induced liver toxicity in rats. Exp Toxicol Pathol. 2012;64:291-5.

24. Missoun F, Slimani M, Aoues A. Toxic effect of lead on kidney function in rat Wistar. African J Biochem Res. 2010;4:2127.

25. Yin ST, Tang ML, Su L, Chen L, Hu P, Wang HL, et al. Effects of Epigallocatechin-3-gallate on lead-induced oxidative damage. Toxicology. 2008;249:45-54.

26. Sheehan D, Meade G, Foley VM, Dowd CA. Structure, function and evolution of glutathione transferases: Implications for classification of nonmammalian members of an ancient enzyme superfamily. Biochem J. 2001; 360:1-16.

27. Antonio-García MT, Massó-Gonzalez EL. Toxic effects of perinatal lead exposure on the brain of rats: Involvement of oxidative stress and the beneficial role of antioxidants. Food Chem Toxicol. 2008:46:2089-95.

28. Wright NJ, Thacher TD, Pfitzner MA, Fischer PR, Pettifor JM. Causes of lead toxicity in a Nigerian city. Arch Dis Child. 2005:90:262-6.

29. Wang J, Zhu H, Yang Z, Liu Z. Antioxidative effects of hesperetin against lead acetate-induced oxidative stress in rats. Indian J Pharmacol. 2013.45: 395-8.

30. Nisar MF, Nasir I, Shaheen S, Khalid A, Tazeen N. Chronic lead acetate nephrotoxicity: A histological study on albino rats. Ann King Edward Med Univ. $2011 ; 17: 239$

\section{Publisher's Note}

Springer Nature remains neutral with regard to jurisdictional claims in published maps and institutional affiliations.

\section{Submit your manuscript to a SpringerOpen ${ }^{\odot}$ journal and benefit from:}

- Convenient online submission

- Rigorous peer review

- Open access: articles freely available online

- High visibility within the field

Retaining the copyright to your article

Submit your next manuscript at $>$ springeropen.com 